Cuadernos del CILHA n 34-2021 | publicación continua

ISSN 1515-6125 | EISSN 1852-9615

http://revistas.uncu.edu.ar/ojs/index.php/cilha/

CC BY-NC 2.5 AR

Recibido: 06/07/2021 Aprobado: 15/07/2021

PP. 1-21

DOI: https://doi.org/10.48162/rev.34.017

\title{
Masculinidad y violencia afectiva en la ficción narrativa de Leticia Obeid y Francisco Bitar
}

\author{
Masculinity and affective violence in the narrative fiction of \\ Leticia Obeid and Francisco Bitar
}

Guadalupe Maradei

https://orcid.org/0000-0001-7276-0648

Universidad de Buenos Aires

guadalupemaradei@gmail.com

Argentina

Resumen: El ensayo lee como texto de la cultura (Barthes, 1971) la reciente publicación de dos ficciones narrativas que experimentan con el género novela y problematizan el desamor como proceso y como conflicto. El corpus está conformado por Preparación para el amor de Leticia Obeid (2015) y La preparación para la aventura amorosa de Francisco Bitar (2021). El análisis focaliza en el modo en que los relatos traman la violencia afectiva como un tipo específico de violencia de género (Martín Sánchez, 2015) y sus relaciones con el paradigma -en crisis- de la masculinidad como dispositivo de poder (Fabbri, 2021).

Palabras clave: Literatura argentina, Género, Amor romántico, Masculinidad, Violencia afectiva. 


\begin{abstract}
The essay reads as a culture text (Barthes, 1971) the recent publication of two narrative fictions that experiment with the novel genre and problematize heartbreak as a process and as a conflict. The corpus is made up of Preparación para el amor by Leticia Obeid (2015) and La preparación para la aventura amorosa de Francisco Bitar by Francisco Bitar (2021). The analysis focuses on the way in which the stories plot affective violence as a specific type of gender violence (Martín Sánchez, 2015) and its relationships with the paradigm -in crisis- of masculinity as a device of power (Fabbri, 2021).
\end{abstract}

Kewords: Argentine literature, Gender, Romantic love, Masculinity, Affective violence.

\title{
I. Mitos de amor romántico: entre la opresión y la internalización
}

"Una obra de arte siempre es contemporánea de un cierto régimen de experiencia estética. Flaubert es contemporáneo de un tiempo donde las hijas de los obreros y de los campesinos buscan integrar en su vida los ideales del arte y de la pasión", aseguró Jacques Rancière en la entrevista "La democracia de Madame Bovary" (Rancière, 2010).

Recientemente, en El fin del amor, Eva Illous (2020) ha indagado el fenómeno por el cual el amor forma parte de la episteme contemporánea, mientras que su reverso, el desamor, ha quedado por fuera de lo pensable, lo decible, lo deseable:

Incontables novelas, poemas o películas nos instruyen en el arte de volvernos discípulos de Platón, de amar la perfección que el ser amado manifiesta. Sin embargo, una cultura que tiene tanto para decir acerca del amor es mucho más silenciosa cuando se trata del momento, no menos misterioso, en el que evitamos enamorarnos, en el que nos desenamoramos, en el que quien antes nos mantenía en vela durante la noche ahora nos deja indiferentes, en el que nos alejamos a toda prisa de quienes nos atraían hace unos meses, o incluso hace unas horas. (Illous, 2020, p. 12)

No obstante, para esta autora, es justamente el desamor el que resulta significativo para la reflexión crítica actual, en la medida en que gira en torno a una descomposición creciente de los lazos sociales. 
En la contemporaneidad, la degradación de las relaciones sociales y de la solidaridad social parece estar estrechamente ligada a la participación voluntaria en redes sociales, a las transformaciones tecnológicas y a una maquinaria que suministra (vende) consejos y ayuda. En ese sentido, el desamor resulta un terreno privilegiado para entender de qué manera la intersección entre el capitalismo, la sexualidad, las relaciones de género y la tecnología produce una nueva forma de (no) sociabilidad.

En la literatura, concebida como agenciamiento colectivo de enunciación (Deleuze, 1996), es posible leer vestigios de estos procesos a partir de la reelaboración ficcional. En manifestaciones recientes de la literatura argentina, dichos procesos se articulan con inflexiones experimentales de la novela (en las cuales la primera y la tercera persona se alternan, se solapan, se espejan) que ruedan a la par de distintos desmoronamientos: el del amor romántico y el de la llamada masculinidad hegemónica (Connell, 2005) en tanto mitos modernos que, si bien durante siglos funcionaron como cohesivas promesas de felicidad, paulatinamente, comienzan a refractar sus violencias constitutivas. Como sostiene Coral Herrera (2018):

El romanticismo patriarcal nos hace creer que el amor es fácil, una energía mágica e inagotable que surge por sí sola y se mantiene igual en el tiempo. En este sentido, el amor es como las religiones, porque nos seduce con el paraíso del amor total. Nos hace creer que hay alguien superior a nosotras que nos ama y nos cuida en la distancia, que nunca nos falla, que siempre nos protege, que nos concede todos los deseos, nos vigila y nos castiga si no nos portamos bien, y no deja de amarnos jamás, hagamos lo que hagamos. Si tenemos fe, el amor nos llevará a la vida eterna; si aguantamos los sufrimientos de este valle de lágrimas, algún día podremos vivir felices en el paraíso romántico. (Herrera, 2018, p. 15)

En efecto, trabajos recientes han indagado en el modo en que el amor romántico, en tanto experiencia jerarquizada en el imaginario de las sociedades occidentales, ha incidido en los procesos de subjetivación de subjetividades socializadas como mujeres desde la Modernidad, ubicándolas, a partir de la internalización de determinados valores y percepciones que responden a la lógica binaria sexo-género, en situaciones 
de vulnerabilidad ante formas de dominación y violencia masculinas (Saiz Martínez, 2013).

Entendemos la masculinidad como aquel dispositivo a cargo de la producción de los sujetos varones hetero-cisexuales (Cabral, 2009) de los que se espera que ocupen posiciones dominantes en el marco de relaciones generizadas de poder.

Siguiendo a Eleonor Faur (2009), consideramos relevante el hecho de que “...no todos los varones viven ni valoran del mismo modo los esquemas de masculinidad hegemónica, pero todos los conocen. Todos han sido de uno u otro modo, socializados dentro de este paradigma (...) varones y mujeres participan en la construcción de la masculinidad como una posición privilegiada. Ellos y ellas colaboran con la creación de esta sensación generalizada de Joseph-Vincent Marqués (1997) sintetiza del siguiente modo: 'Ser varón es ser importante' y 'tener que ser importante'” (Marqués, 1997, p. 19).

Desde el campo psicoanalítico, Irene Meler (2010) ha indagado cómo en la clínica se hacen visibles distintas formas de mistificación del amor en las que las referencias a la pasión amorosa encubren dominaciones y dependencias: "es imposible discriminar con claridad en qué medida los sentimientos amorosos u hostiles se asocian con relaciones de dominio y dependencia, o sea con cuestiones relacionadas con el apego, asociado, a su vez, con la autoconservación y con el narcisismo del sujeto. El poder se erotiza, tanto en sus aspectos dominantes como en las formas eróticas de la 'entrega' y la dependencia del otro. El deseo y el placer sensual, a la vez, otorgan poder sobre el semejante" (Meler, 2010, p. 63).

Pero ese dispositivo de poder llamado masculinidad es el que hoy se encuentra interpelado por una ola feminista que cuestiona los pactos sexuales y órdenes de género en que se producen y reproducen las relaciones de opresión, explotación y violencias machistas (Fabbri, 2021, p. 6).

En ese punto, el círculo aparentemente perfecto que anudaba la internalización del amor patriarcal con los mecanismos de opresión de la dominación masculina (Bourdieu, 2003) va mostrando deformaciones y fisuras.

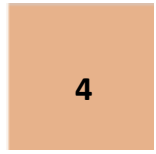


Este ensayo se propone leer como texto de la cultura (Barthes, 1971) la reciente publicación de dos ficciones narrativas que experimentan con el género novelesco y problematizan el desamor como proceso y como conflicto. El corpus está conformado por Preparación para el amor de Leticia Obeid (2015) y La preparación para la aventura amorosa de Francisco Bitar (2021). El análisis focaliza en el modo en que los relatos traman la violencia afectiva como un tipo específico de violencia de género (Martín Sánchez, 2015) y sus relaciones con el paradigma en crisis- de la masculinidad como dispositivo de poder (Fabbri, 2021).

\section{Leticia Obeid: qué se puede hacer salvo ver películas}

Preparación para el amor (2015) es la tercera novela de la escritora y artista visual cordobesa Leticia Obeid.

De manifiesta inspiración barthesiana -en el marco de una producción sinestésica interesada en el problema de la lectura, la mirada y la voz- Obeid enlaza dos clásicos de la teoría postestructuralista francesa (Preparación de la novela y Fragmentos de un discurso amoroso) para provocar un desplazamiento sintomático de un cambio de significación tanto de la escritura de ficción como del acto de enamorarse.

El libro experimenta con géneros, registros y temporalidades, con una constante intertextualidad literaria y cinematográfica. Si el cuerpo central del relato condice con varios rasgos del género "diario íntimo" o "diario de viaje", la autora interviene ese conjunto de enunciados relativamente estables para arribar a otro tipo de textualidad, absolutamente experimental.

El relato de las peripecias del viaje (al encuentro del amado) sufre dos intervenciones. Por un lado, la construcción de un relato marco que, a la inversa de la novela tradicional, acude a una tercera persona que luego abandona en el cuerpo del diario, narrado en primera. Y, por otro, la profusión de citas, anotaciones, fotografías, reflexiones, realizadas a posteriori de la escritura del diario, marcando una deliberada heterocronía. 
El motor del relato es una consigna de escritura que se narra en la primera entrada del diario:

(19_11_2012)

Mientras me tomaba el café leí una frase en una nota de Philip Roth, que me quedó ahí girando todo el día, decía así:

Si se escribe una página al día, al año tendrás 365 páginas y, por lo tanto, un libro. No es una hazaña ni un gran esfuerzo." Me pareció una buena idea, cercana y posible, aunque luego me di cuenta de que lo difícil no es escribir una página por vez sino decidir en qué arroyo se vuelcan esas palabras. ¿Tiene que haber coherencia? Imagino que al menos tiene que haber un hilo que una esas páginas para que se conviertan en un libro.1. Uno. (Obeid, 2013, p. 45)

De inmediato, la asunción de este proyecto genera interrogantes respecto de las relaciones posibles entre escritura, literatura y vida. En primera nota al pie del diario se lee:

¿Qué cosa aglutina una serie de textos? ¿Es la existencia de un proyecto, la identidad en común entre ellos, la práctica diaria, el volumen alcanzado, el deseo de ser autor? ¿Cuándo un libro es un libro? ¿Un libro es algo que sólo un escritor puede hacer? ¿Cuándo alguien se vuelve escritor o escritora? ¿Quién lo decide? ¿Un libro debe tener introducción, nudo y desenlace? ¿Una historia de amor, también? ¿Las relaciones, son siempre historias? ¿Las historias son siempre relaciones? Relaciones novela, relaciones-cuento, relaciones-poema, relaciones haiku, relaciones-documental, relaciones-melodrama, relaciones-ensayo, relaciones-videoclip. (Obeid, 2013, p. 46)

La reflexión metatextual atravesará la superficie del texto al que la narradora llama "texto enamorado": "El texto enamorado es un texto con funciones muy particulares, es como una especie de conjuro para sostener un estado, una forma, extender un momento o volverlo espacio. [...] El enamoramiento va colonizando más y más territorios hasta que llega un momento en que todo parece pertenecerle" (Obeid, 2013,

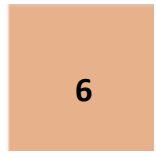


p. 82). En este punto, el diálogo con Preparación de la novela de Roland Barthes se hace patente pero también su diferenciación. Si la pregunta en Barthes parecía ser ¿qué pasa cuando un crítico quiere escribir porque ama?, en Obeid el enigma es ¿qué pasa cuando un escritor o escritora escribe porque quiere amar?

Las peripecias del personaje marcan un movimiento hacia el reencuentro, hacia el acortamiento de una distancia geográfica (Buenos Aires-Berlín). El marco del relato acentúa el contraste entre la preparación y la sustanciación de ese reencuentro: “Al planificar este último viaje tuvo la convicción de que nada podía salir mal. Había preparado todo con serenidad y alegría. Estaba enamorada y convencida de estar haciendo la cosa más perfecta de su vida" (Obeid, 2013, p. 25).

Ese contraste entre las expectativas y los hechos, entre lo que se espera del amor y lo que finalmente sucede, al que la narración apunta dentro y fuera del diario, refracta rasgos distintivos del período que Eva Illous denomina "modernidad hiperconectada". El primer encuentro se produce en el marco de un festival internacional de cine en Buenos Aires y el segundo y último encuentro, en un festival de cine en Berlín, marcando el pulso del funcionamiento habitual del circuito de ferias, bienales y festivales internacionales en el marco de un sistema del arte tan globalizado como precarizado para los artistas (Fleck, 2021). Pero son las redes sociales las que posibilitan y aceleran los encuentros. La invitación inicial se mediatizó vía Facebook (“Al día siguiente me encontró en Facebook y me invitó a tomar algo antes de la película de las 8" (Obeid, 2013, p. 64)) y la relación a distancia se sostuvo a través de Skype:

El Skype es una forma de cortejo muy espiritual. Prepara, acerca, pone la imagen en un lago de agua que refleja a los que conversan y ancla la comunicación a un punto fijo. No se siente como algo que acompaña a la acción, como el hablar; se siente como la acción misma, casi como un trabajo, aunque se pueda llegar a un estado contemplativo. Algunos enamorados dejan el Skype abierto toda la noche, cuando se van a dormir. 
Si uno se despierta antes que el otro, puede llegar a ver imágenes muy extrañas. (Obeid, 2013, p. 94)

Pero, así como acortan los tiempos del encuentro, las redes sociales, en tanto archivo, acortan también los tiempos de la decepción, como se aprecia en la nota al pie 51, que comenta una entrada del diario correspondiente a la primera y compleja semana de convivencia con K. en Berlín:

Yo le pedía la computadora y él me la pasaba con su correo, su Facebook y su Skype abiertos. Un día no soporté la tentación y me asomé al FB y vi una serie de chateos con diversas mujeres, más o menos recientes. Elegí uno y lo abrí. Era una chica turca que parecía conocer Buenos Aires. La conversación era galante, ella respondía con simpatía, pero sin zarparse y le contaba que desde su balcón en Estambul veía el mar y entonces él le contestaba que en mayo probablemente fuera para allá y que le gustaría pararse en ese balcón a ver la vista. Remataba la frase con un emoticón (-). La frase me dejó perpleja, no sólo por celos -y no habían todavía hecho ningún arreglo en torno al tema de la fidelidad- sino porque el hecho de que él estuviera planeando un viaje para después de mi partida indicaba que ya tenía otros planes sin mí, incluso desde antes de que yo llegara (la charla databa de mediados de enero). O sea, había un final ya prefigurado en su cabeza, o al menos un orden que me contemplaba sólo como una fase pasajera. Y, por mi parte, yo lo había etiquetado tan rápidamente como el amor-de-mi-vida [...]. (Obeid, 2013, p. 222)

La carencia de lo que desde la década de 1980 empezó a teorizarse en términos de "responsabilidad afectiva" contrasta no sólo con la idealización del comienzo del relato sino también con la serie de demandas, sugerencias, exigencias, orientadas a un determinado canon de belleza que el personaje socializado como varón manifiesta a la narradora en distintas instancias:

Anoche tuvimos una discusión seria, que empezó por un motivo banal y muy vergonzoso, que por cierto ya se lo conté a unas cuantas amigas para ir haciendo

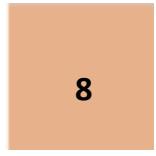


un promedio de opiniones sobre la depilación en tira de cola y el derecho a pedirla. Parece que marcha muy bien y que todos la piden. Parece que duele mucho, también [...] desde que nos conocemos con $\mathrm{K}$, hace tan poquito tiempo, ya hemos hablado un montón sobre mi aspecto físico y sus sutiles sugerencias: que mantener el peso (mejor incluso sería bajarlo), que el bronceado, que el corte y la tintura, que las uñas pintadas, la natación, el sauna y los vestidos femeninos. Nomás faltaba este último pedido". (Obeid, 2013, p. 136)

En este punto se activa un elemento relevante que estará presente también en la novela experimental de Francisco Bitar: la memoria familiar de la violencia afectiva. EI padre que denigra aparece fantasmáticamente repitiendo y amplificando la escena decodificada en términos de mecanismo de disciplinamiento, desde una mirada crítica de las relaciones de género en tanto relaciones de poder:

Una de las primeras peleas adolescentes que tuve con mi padre fue porque él le criticaba cosas del aspecto físico a mi madre; decía que tenía brazos gordos, tobillos gruesos, cosas así. Mi madre tiene un cuerpo común, pero tiene además algo que la hace hermosa, indefinible, no se sabe si son los rasgos, la personalidad, algo así como un aura o un campo magnético que genera. Esas cosas que decía padre me daban bronca porque mi madre no se defendía -a lo sumo se ofendía- pero también por mí misma, porque veía que yo me parecía a mi madre en esos rasgos y me sentía entonces criticada también. Es bastante feo, pienso ahora, que cualquier persona le diga esas cosas a otra. Pero cuando un hombre lo hace con una mujer, es como si le disputara su propio dominio de femineidad. ¿Qué son esos comentarios estéticos, deseos, pedidos, identificación, mortificación? ¿Es acaso un ideal que se contrapone al cuerpo real, al cuerpo en sí, o es un reproche sobre el uso que la dueña hace de ese cuerpo? Como si dijéramos: "yo, si tu casa fuera mía, sabés cómo la tendría, ¿no?". (Obeid, 2013, p. 137)

Se configura así en la narración un malestar creciente vinculado con un sentimiento de asimetría, que se confirma en el nivel disímil de participación que registra la narradora 
en el ámbito privado respecto de la esfera pública. De un lado, el papel de cuidadora esencial que se le propone en el incipiente hogar: "Anoche me pidió ayuda para cambiarse la venda, ponerse la camiseta y lavarse el pelo, como si necesitara confirmar que puedo hacerlo. A mí me gusta, pero también me sorprende el tono de marido que le aparece, es una mezcla de hombre grande y niño, dulce y demandante a la vez" (Obeid, 2013, p. 156). Un papel y un gusto que, además, no son recíprocos:

Las valijas aún no llegan. Empezamos el día ya con chinche. Él está siguiendo su rutina sin mover casi medio centímetro. Tiene un ataque de productividad. Y no me ayudó en nada (...) está enfrascado en sus cosas, chateando con otras minas, molesto por la operación, no se baña, no se pasa ni una toalla húmeda, y sólo habla de sus asuntos. Es un desastre. ¿Qué hacer con el enojo? ¿Dónde empieza, dónde termina?

No puedo parar de pensar en los esfuerzos que hice para estar acá y también cuando él estaba allá, y la manera en que automáticamente me adapto a él y a lo que él necesita o yo creo que él necesita, y lo desigual que es esto. (Obeid, 2013, p. 159)

Del otro lado, la invisibilización sistemática de su actividad artística y profesional (pero también del vínculo que ella piensa que los une) en los intercambios sociales de los que participan: "A veces él me presentaba, de entrada, con mi nombre y alguna definición. Pocas veces decía que yo hacía video, o arte. Generalmente me presentaba como escritora. $Y$ otras veces, en especial cuando se trataba de encuentros con gente importante del cine o del arte, directamente era capaz de ignorarme, de cerrar el diálogo corporalmente, dándome la espalda o mirando en otra dirección..." (Obeid, 2013, p. 230).

Ese sentimiento de desvaloración se pone en abismo hacia el final del diario, en la nota al pie 53, donde se narra una escena de identificación a partir de un film que la narradora elige ir a ver para tomar distancia y que vale la pena citar in extenso:

No pude entender en ese momento el impacto tan oportuno como doloroso de esas imágenes y de la película, que llegaba en el peor momento, a hablar de esa

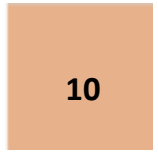


asimetría entre los artistas y entre los amantes, acentuando la idea de que la locura es realmente un resultado de ello. La película describe esos primeros diez días después de que a Camille Claudel la internan en un manicomio y cómo, en ese corto período, ella experimenta un cambio entre sus primeros intentos de escape, de rebelarse contra esa decisión que ha tomado su familia, cuando ella ya es una artista de casi cincuenta años, ya ha hecho lo mejor de su obra, ya ha terminado su historia tormentosa con Rodin -de quien se dice que le robó a ella ideas, y estilo- y a causa de sus crisis nerviosas la encierran para siempre, puesto que allí, una vez que se resigne, vivirá los últimos treinta años de su vida, sin hacer nada más, nunca nada más, porque ni siquiera su hermano, el poeta Paul Claudel, atiende a sus súplicas. Vi la película en un cine enorme y antiguo, refaccionado para que entraran como mil personas. $Y$ vi el paisaje gélido del invierno europeo magnificado en la pantalla. Salí de ahí muy triste y la vuelta a casa no fue mejor: las cosas no habían cambiado entre nosotros, como casi no han cambiado entre los y las artistas, en cien años. Un poco sí, pero no tanto, pensé. (Obeid, 2013, p. 234)

Irene Meler (2020) ha indagado en qué medida la asimetría existente entre las posiciones sociales de los enamorados ha favorecido el desarrollo de actitudes de intensa dependencia emocional de las mujeres con respecto de sus compañeros. En la actualidad se vive un tránsito de la idealización del sentimiento amoroso, concebido como la llave de la felicidad, sobre todo por las mujeres, a su impugnación des mistificadora. Hoy bailamos sobre las ruinas del edificio del amor romántico, indica Meler, que ha inspirado tantas creaciones literarias, y que ha sido constituido en la clave del proyecto vital de mujeres de varias generaciones.

En contraposición, "los hombres no se tomaron muy en serio la idealización amorosa. Una vez superada la adolescencia, los afanes vitales masculinos se han destinado a los logros personales, a la prosecución de triunfos que los calificaran y ubicaran en buena posición al interior del colectivo viril. De modo que la ilusión amorosa, cultivada a través de la literatura y el cine, fue develada como una argucia patriarcal para garantizar el 
usufructo masculino de la sexualidad y de la capacidad reproductiva de las mujeres, asegurándose descendientes legítimos" (Meler, 2020).

El libro de Obeid se atreve a narrar ese desacople, ese desencuentro constitutivo de las relaciones humanas en un sistema binario y jerarquizado de sexo-género y en un occidente capitalista, generador de vidas precarias volcadas a la subsistencia y competencia desenfrenada, fagocitador de la energía creadora del arte y de la potencia de los cuerpos en conexión (Rolnik, 2007). Pero también narra un deseo de escritura que va más allá de posibles ajustes de cuentas, de la catarsis y la victimización: la escritura como proyecto político y como tecnología de subjetivación.

\section{Francisco Bitar: mi amor, no te puedo amar}

La preparación de la aventura amorosa (2021) es la segunda novela y se anuncia como el primer volumen de la serie De ahora en adelante, del escritor santafesino Francisco Bitar.

La imagen de cubierta, una serie de retratos de muchachas jóvenes (Daniel García, "Damas de Shangai", 2018), anticipa la lógica del harem, el catálogo de mujeres tanto del pasado del personaje como de potenciales conquistas, que la narración revisa como forma de preparación para lanzarse a una nueva aventura amorosa. Una línea de fuga hacia adelante que enhebra escenas de abandonos compulsivos, una sucesión de despedidas cuyos niveles de desapego y emotividad contenida refuerzan su efecto gracias al procedimiento del estilo directo, al despojo de la mediación narrativa.

La novela comienza con una imagen onírica. Se trata de un sueño protagonizado por la madre del narrador, que se repite desde sus nueve años. En el sueño, la madre es arrollada por un auto y muere. En la agonía, dos mandatos: la ambivalencia y la soledad: "antes de morir, sale de su eterno mutismo. Le dice que no deje de ir al cine [...] no le devuelve ninguna clave, ninguna respuesta sino a lo sumo algo parecido a una idea poco clara que se contradice en sus términos: 'el sí-no' al que lo devuelve su sonido" (Bitar, 2021: 10) 
Y luego, enfatizado por la segunda persona y el discurso directo: "Vos solo vas a tener que decidir cuál es el significado cada vez, en los capítulos que tu vida amorosa se hace o se deshace (es decir, en tu habilidad, pero sobre todo en tu ineptitud para acercarte a una nueva mujer). Vos solo vas a tener que decidir qué cosa es el amor" (Bitar, 2021, p. 11)

Después del relato del sueño, los capítulos se organizan en torno a las peripecias de la vida del joven Cerro, onomástico que juega a la vez con la medianía, con el hombre cualquiera, parte del paisaje, al igual que sus amigos, primero nombrados como "Uno" y "Otro", y a partir del capítulo 6, aludidos como "Lomas", "Colina", "Duna", "Montagno", y con la idea de cerrazón, de cerrojo.

El primer capítulo narra un abandono espejado en un tono pendular, que va de lo liviano a lo solemne, y da cuenta de una imposibilidad de verbalizar emociones de los dos personajes socializados como varones, Cerro y su padre, que se cruzan de madrugada y sostienen el siguiente diálogo:

Un suegro es un suegro, dice el padre luego de un instante, volviendo de su trance.

Supongo, dice el chico.

Vas a ver.

Es el primero que tengo, dice el chico con una sonrisa.

Mi primer suegro en serio, agrega.

Preparate, dice el padre, van a ser todos más o menos parecidos.

Supongo, dice el chico, y pasa la vista por la valija. 
Más que hacer el equipaje cada lunes para esos viajes de trabajo, está mudando su ropa en partes, dijo hace poco su madre.

Tampoco debe ser fácil para el tipo, dice el padre.

Sobre todo cuando es la primera vez, agrega.

Ahora sí: el chico se ceba un mate.

Debe sentirse viejo, dice el padre.

Bueno, no sé si viene tan en serio la mano, dice el chico en voz baja, más baja que antes.

Ah, suelta el padre.

Sí, dice el chico.

Bueno, recién arrancan la facultad, dice el padre.

Ya sé: un mundo de posibilidades, dice el chico.

El padre lleva los ojos hacia arriba en un gesto de exageración.

Ya lo creo, dice.

El chico se toma el mate de golpe y con ruido: tiene miedo de empezar a lagrimear.

Entonces que te odie todo lo que quiera, dice el padre.

Cómo.

Tu suegro, dice el padre. Que te odie en paz.

El chico ha logrado contener el llanto y el padre aprovecha ese silencio: 
Bueno, dice el padre.

Ahora sí: se está despidiendo.

Gracias por tus mates indios, dice el padre, y antes de que el chico tenga posibilidad de responderle, las rueditas de la valija, han cruzado el comedor y salen por la puerta de calle. (Bitar, 2021, p. 19)

A continuación de esa escena, se encadena otra despedida que por yuxtaposición puede pensarse como motivada por la primera. Cerro despierta a la novia a la cual se refería en la conversación con el padre hacía un momento, que estaba durmiendo en un cuarto cercano:

¿Te pudiste cruzar con tu papá?, pregunta la chica.

Te tenés que ir, dice el chico.

Cómo, dice la chica.

¿Es mi aliento?, agrega ella y vuelve a sonreír.

Que te vayas.

Ahora ella está despierta, con los ojos, aunque hinchados, atentos e interrogativos. Él nunca olvidará esta cara.

¿Ahora?, pregunta la chica incorporándose.

Estoy apurado, dice el chico.

¿Qué tenés que hacer?, pregunta ella. 
Tengo que hacer, dice el chico, pero, más allá de lo que ha dicho, no tiene una respuesta precisa.

Solo sabe que no se puede detener.

Ni siquiera puede demorarse. (Bitar, 2021, p. 21)

Si las aventuras del joven Cerro pueden leerse como una novela de formación, en el relato la madre es quien le enseña a estar solo, el padre es quien le enseña a abandonar. Luego de ese primer abandono vienen años de vagabundeo, orfandad y desempleo y una actitud de acedia, que quedará como rasgo saliente del personaje en las distintas etapas que atraviesa el relato.

En narrador remata el cuadro de situación refiriéndose a su situación sentimental:

Por supuesto, tampoco tiene novia.

Luego de una época de cacería indiscriminada (con algunas conquistas dignas de recordar, pero con una suerte cada vez más esquiva), se ha vuelto un perfecto inepto a la hora del encare.

Sus intentos no tienen fuerza, y si la tienen es la fuerza de la obligación, azuzada por el alcohol y el contexto: al fin y a I cabo, Cerro transita la época de la juventud, es decir, de la abundancia, y se espera de él que aproveche al máximo su situación. (Bitar, 2021, p. 23)

La relación amorosa, en la novela de Bitar, siempre se encuentra definida en términos de cacería, conquista, o cosecha de mujeres (nunca en términos de encuentro, de acción conjunta o de cacería efectuada por mujeres). $Y$ su concreción depende enteramente de la capacidad, habilidad, voluntad y entrenamiento de los sujetos socializados como varones. Además de la pasividad respecto de las relaciones, los personajes socializados como mujeres en esta narración no tienen nombre ni circulan por el espacio público (se nombran como "su madre", "su tía", "su mujer", "su novia",

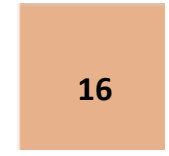


"Primer amor", "su alumna"). Se esconden para tener sexo. Planchan. Hacen la valija. Organizan las vacaciones familiares y los eventos con amigos. Venden ropa en un local comercial. Cuidan nietos.

A partir de un salto temporal, el relato pasa a la madurez del personaje para narrar que, cuando su esposa está embarazada de su primer hijo, Cerro sueña con "Primer amor" e interpreta ese sueño como un signo de que la relación entre ambos (que él finalizó) había quedado inconclusa. A través de dispositivos electrónicos y redes sociales, comienza un proceso idílico y silencioso de re enamoramiento. Los mensajes de despedida guardados en el correo electrónico son consultados una y otra vez y su lectura funciona como un viaje al pasado. Las redes sociales, a las cuales ingresa por primera vez por el frenesí de generar un encuentro con aquel amor, funcionan como archivo y canal de encuentro. Luego de una práctica obsesiva de "stalkeo", Cerro empieza a merodear los lugares que aparecen en las fotos de Facebook de "Primer amor". Así se acera y entabla una relación con la hija de nueve años a quien va a ver jugar a la plaza. Siempre que logra hablar con la niña, experimenta un resurgimiento de la energía sexual y tiene noches de sexo salvaje con su esposa. Como conclusión de estas excursiones, en paralelo a la consolidación de su proyecto familiar, decide que desea "volver al juego" y "una vida otra vez en movimiento".

En el capítulo 5, revisa su prontuario amoroso y elabora una lista de las novias que tuvo desde los cinco años en adelante, ordenando la información a partir de las siguientes variables: Edad de Cerro, Situación de encare, Rasgo que prevalecerá. En esa revisión descarnada, se hace mención tanto a cuestiones de clase (lo inesperado que fue que la hija de un médico reparara en él, hijo de profesores) como a mandatos sociales de belleza y virilidad: "La cuestión del desarrollo de los cuerpos ha quedado atrás: se da por sentado que ya no son niños. Ahora empieza algo peor, una competencia abierta y descarnada en los fuertes y los débiles que quizá nunca más encuentre tregua [...] Por supuesto, lo deprimen también sus nuevas compañeras. Ninguna es linda [...]" (Bitar, 2021, p. 127). 
En este punto y en la curva que lleva a la profecía autocumplida de un nuevo abandono (ahora de su mujer y dos hijos, y, otra vez, gestado en silencio) la novela de Bitar lleva hasta las últimas consecuencias la apuesta de acompañar la deriva de un varón argentino promedio sin enjuiciamientos, justificaciones, heroísmos ni redención.

En ese sentido, Preparación de la aventura amorosa, podría leerse como epopeya de "un hijo sano del patriarcado", un término utilizado en los últimos años para circunscribir el fenómeno del femicidio y la violencia contra las mujeres como un problema estructural (no se trata de monstruos, de animales, ni de manadas, sino de varones socializados en nuestras escuelas, en nuestras familias, en nuestra comunidad), pero que puede extenderse a las llamadas micro violencias, entre las que se cuenta la violencia afectiva, que Rita Segato (2003) consideró propias de un régimen de colonialidad:

Las estructuras elementales de la violencia residen en la tensión constitutiva e irreductible entre el sistema de status y el sistema de contrato. Ambos correlatos y coetáneos en el último tramo de la larga prehistoria patriarcal de la humanidad. El sistema de status se basa en la usurpación del poder femenino por parte de los hombres. Ese efecto violento resulta del mandato moral de reducir y aprisionar la mujer en su posición subordinada, por la marca de género, raza, etnicidad, nacionalidad, región, o cualquier inscripción que opere en el tipo de estructura de relaciones que llamamos hoy de colonialidad, recurriendo a la violencia sexual, psicológica y física, o manteniendo la violencia estructural del orden social y económico en lo que hoy los especialistas ya están describiendo como la "feminización de la pobreza". (Segato, p. 35)

Finalmente, el periplo insatisfecho de Cerro exhibe, como argumenta Sandra Russo (2020), el hecho de que los varones también necesitan dejar de sufrir: " todos creemos, muchas veces, que sufrimos por amor, pero la verdadera causa de nuestro dolor no es esa, sino la precarización de nuestras vidas, lo vulnerables que somos, la hoja al viento que muchas veces nos sentimos porque no somos dueños de nuestras decisiones,

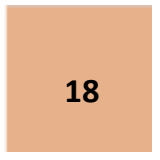


tomamos las sobras de un sistema que no fue pensado para nuestra dicha, sino para la de una ínfima cantidad de gente" (Russo, 2020, p. 70).

\section{El deseo de cambiarlo todo}

La puesta en serie de dos novelas experimentales (de la era de las redes sociales pero previas a las hoy tan populares apps de citas como Tinder), que se proponen narrar el deseo de amar o de vivir una aventura amorosa y terminan narrando el desencuentro, la soledad y el desamor, permite vislumbrar un proceso de resquebrajamiento de la idealización del romance y del amor muy distante de la concepción de lo amoroso en el melodrama y en la tragedia clásica pero también disímil del lugar sagrado y revelador que le adjudicaron intelectuales de la segunda mitad del siglo XX como Julia Kristeva, Georges Bataille o Roland Barthes.

Asimismo, la similitud matizada en los títulos de ambas novelas evidencia una diferencia que proviene de un antagonismo, de una puja entre conservar los privilegios o vivir juntos con marcos éticos tendientes a la igualdad y la responsabilidad.

La diferencia entre el "amor" como proyecto y construcción de verdad (Badiou, 2010) y la "aventura amorosa" como pasatiempo sin responsabilidad afectiva habilita a leerlos como reelaboraciones ficcionales complementarias, como frente y reverso del mismo proceso.

El deseo de cambiarlo todo que manifestaron los feminismos en los últimos cinco años abarca también estos procesos escasamente narrados. En La potencia feminista, Verónica Gago (2019) reflexionó en torno a la masividad y radicalidad de esa experiencia política que desbordó las calles y transformó la gramática de diversas luchas. Su investigación, escrita en clave de investigación militante, al calor de las asambleas y los paros, esboza un diagnóstico de la crisis que permite poner en conexión las violencias económicas, financieras, políticas, institucionales, coloniales y sociales; la necesidad de instaurar nuevas rebeldías, evitando el punitivismo y la victimización; y lanzando una impugnación concreta a la razón neoliberal. En una coyuntura de 
emergencia de una contraofensiva neoliberal y conservadora y de propagación de discursos de odio, la apuesta por un feminismo transversal, ligado a los conflictos en los distintos cuerpos y territorios, es la posibilidad de elaborar una teoría alternativa del poder fundada no una toma del poder que instaure una nueva jerarquía sino en el deseo de cambiarlo todo.

Al mismo tiempo, como indicó Dora Barrancos (2019), el feminismo deconstruye la idea del amor romántico, que se basa en relaciones de poder y prácticas muchas veces violentas, para construir nuevos vínculos desde el cuidado y el diálogo. Con el fin del ideal del amor romántico, pierden vigencia los roles estereotipados y la presunción de que solo pueden existir relaciones heterosexuales monogámicas y coito céntricas, abriendo la puerta a diversas maneras de demostrar el amor y vincularse.

Alan Badiou (2010) escribía no hace mucho: "el amor debe reinventarse, pero, también, sencillamente, debe ser defendido porque se encuentra amenazado por todas partes" (Badiou, 2010, p. 56) En esa transición, en la literatura argentina, las subjetividades que no se sienten amadas o capaces de amar según el paradigma de amor tradicional (las estirpes condenadas a cien años de soledad, según la lengua exotizada del boom de la literatura latinoamericana) reclaman un nuevo régimen de experiencia estética, un desplazamiento del reparto de lo sensible que reconozca sus vidas como susceptibles de ser narradas, más allá de los marcos moralizantes del melodrama o la tragedia.

\section{Referencias}

Badiou, A. (2010). Éloge de l'amour. Flammarion.

Barrancos, D. (2019). Central, espacio de ideas [conferencia]. https://sinmiga.com/2019/10/23/dorabarrancos/

Barthes, R. (1971, septiembre). De l'oeuvre au texte. Revue d'Esthetique, 1 (3), 20-25.

Barthes, R. (1999). Fragmento de un discurso amoroso. Siglo XXI.

Barthes, R. (2005). Preparación de la novela. Siglo XXI.

Bitar, F. (2021). Preparación para la aventura amorosa. Tusquets.

Bourdieu, P. (2000). La dominación masculina. Anagrama.

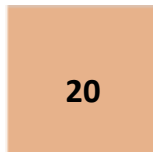

Cuadernos del CILHA n 34 - 2021

ISSN 1515-6125 | EISSN 1852-9615

CC BY-NC 2.5 AR

http://revistas.uncu.edu.ar/ojs/index.php/cilha/ 
Cabral, M. (2009, junio 5). Cisexual. Suplemento Soy. Página 12. https://www.pagina12.com.ar/diario/suplementos/soy/1-803-2009-06-05.html

Connell, R. (2005). Masculinities. University of California.

Deleuze, G. (1996). Crítica y clínica. Anagrama.

Fabbri, L. (2021). La masculinidad incomodada. UNR y Homo Sapiens.

Faur, E. (2009). Masculinidad. En S. B. Gamba (Coord.), Diccionario de estudios de género y feminismos (pp. 150-152). Biblos.

Fleck, R. (2014). El sistema del arte en el siglo XXI. Museos, artistas, coleccionistas, galerías. Mar Dulce.

Gago, V. (2019). La Potencia feminista. O el deseo de cambiarlo todo. Tinta Limón.

Herrera, C. (2018). Mujeres que ya no sufren por amor. Transformando el mito romántico. Los libros de la catarata.

Illous, E. (2020). El fin del amor. Una sociología de las relaciones negativas. Katz.

Lutereau, L. (2020). El fin de la masculinidad. Cómo amar en el siglo XXI. Paidós.

Lutereau, L. (2021, mayo 27). Hoy por hoy casi nadie quiere amar aunque digan lo contrario. Página/12. https://www.pagina12.com.ar/344242-luciano-luterau-hoy-por-hoy-casi-nadie-quiere-amar-aunque-di

Marqués, J.-V. (1997). Varón y patriarcado. En T. Valdés, J. Olavarría (Eds.), Masculinidad/es: Poder y crisis (pp. 17-30) ISIS-FLACSO.

Meler, I. (2010). Amor y poder entre los géneros. Subjetividad y Procesos Cognitivos, 14 (1) 187-203. https://dialnet.unirioja.es/servlet/articulo?codigo $=5217008$

Meler, I. (2020, enero 8). Acerca del amor. Página/12. https://www.pagina12.com.ar/240739-acerca-delamor

Obeid, L. (2013). Preparación para el amor. Caballo Negro.

Rancière, J. (2010, diciembre 21). La democracia de Madame Bovary. Jacques Rancière explora las relaciones entre arte y política. Entrevistado por B. García Jaén. Público. https://www.publico.es/culturas/democraciamadame-bovary.html

Rolnik, S. (2006, diciembre). Geopolítica del rufián. Ramona, 1 (69), 60-68. http://www.ramona.org.ar/node/14565 
Russo, Sandra (2020). La reinvención del amor. Desafíos emocionales contemporáneos. Debate.

Saiz Martínez, M. (2012). Amor romántico, amor patriarcal y violencia machista. Una aproximación crítica al pensamiento amoroso hegemónico de occidente. [Tesis de máster universitario en estudios feministas, Universidad Complutense de Madrid] Repositorio Institucional. https://www.ucm.es/data/cont/docs/3292013-12-17-TFM\%20M\%C3\%B3nica\%20Saiz.pdf 